\title{
Effect of Aloe Vera Gel versus Normal Saline on Pain Relief and Healing Process of Episiotomy
}

\author{
Prof. Rasha Essa ${ }^{1}$, Assist. Prof. Noha Mohamed ${ }^{2}$,Dr. Hanan Kandeel ${ }^{3}$ \\ ${ }^{1}$ professor of Obstetrics and Gynecologic Nursing Faculty of Nursing, Damanhour University. \\ ${ }^{2}$ Assistance professor of Obstetrics and Gynecologic Nursing Faculty of Nursing, Alexandria University. \\ ${ }^{3}$ Lecturer of Obstetrics and Gynecologic Nursing, Faculty of Nursing, Alexandria University. Egypt. \\ * E-mail of the corresponding author: drnohahassan2009@gmail.com
}

\begin{abstract}
Introduction: Spontaneous or episiotomy-induced damage to the genital organs during delivery affects the quality of active labor, especially among primiparous women. It is frequently observed during delivery and can have detrimental effects on a mother's health and quality of life. Aim of the study to determine the effect of Aloe Vera gel versus normal saline on pain relieve and healing process of episiotomy. Materials and method: Design: A comparative quasi-experimental research design was utilized. Subjects: A convenience study subject of (120) women were selected from EL-Shatby Maternity University Hospital. Tools: Four tools were used by the researchers to collect the necessary data: Tool I: basic data structured interview schedule, Tool II: Pain Intensity Visual Analogue Scale (VAS), Tool III: Wound Healing REEDA Scale and Tool IV: Bacteriological Wound Study. Results: There was a statistically significant differences between both groups in relation to perineal pain intensity after 10 postnatal days $\left(\mathrm{X}^{2}=7.937, \mathrm{p}=0.005\right)$. On the $10^{\text {th }}$ postpartum day, the entire Aloe Vera group did achieve complete healing of episiotomy wound compared to $80 \%$ of the normal saline group. There was a statistically significant difference between both groups $(\mathrm{p}<0.0001)$. Conclusion: it could be concluded that the application of Aloe Vera gel was more effective on wound healing and perineal pain than normal saline among postnatal women with episiotomy. Moreover the growth of the isolated organisms among the episiotomy wound treated with the Aloe Vera gel were less than among those treated with normal saline.
\end{abstract}

Keywords: postpartum, episiotomy, Aloe Vera Gel and normal Saline

DOI: $10.7176 / \mathrm{JHMN} / 70-09$

Publication date: January $31^{\text {st }} 2020$

\section{Introduction}

There is no doubt that pregnancy; childbirth and postpartum recovery represent physical and emotional stress on women. The prevalence of serious maternal and related childbirth problems in developing countries is particularly tragic because of the crucial roles that women play in most of these societies. The majority of approximately 140 million births that occur globally every year are related to women without risk factors for complications either for themselves or their babies at the beginning and throughout the process of labour. Nevertheless, the birth moment is critical to the survival of women and their babies, as the risk of morbidity and mortality can considerably increase when complications arise. In line with the targets of Sustainable Development Goal 3 and the new Global Strategy for Women's, Children's and Adolescents' Health (20162030), global health care agencies are expanding their focus to ensure that women and their babies not only survive labour complications should they occur, but also thrive and reach their full potential for health and life.

World Health Organization (2018)

The postnatal period is expected to be a joyous experience, yet it implies numerous dramatic 
physiological, psychological and social changes as mothers adjust to a given birth. Though these changes are normal, they pose great demands on mothers' adaptive capacity. Thus, this critical period deserves more attention and consideration from maternity care providers to ensure mothers' positive adaptation and safe passage. As during this fateful period in women's lives, several problems may quickly develop leading to maternal mortalities and serious long-lasting morbidities. Much of the postnatal morbidity arises from perineal trauma. Perineal trauma or genital tract injury occurs in more than $65 \%$ of all vaginal births and is generally the result of either spontaneous laceration or episiotomy. Bele S(2014)

Episiotomy is a surgical incision of the posterior vaginal wall, perineal muscles, and skin to increase the diameter of the vaginal outlet to facilitate delivery, especially performed among primiparous women Carroli and Mignini, (2009). Spontaneous or episiotomy-induced damage to the genital organs during delivery affects the quality of active labor, especially among primiparous women. It is frequently observed during delivery and can have detrimental effects on a mother's health and quality of life. The first performance of episiotomy was done in 1742, when perineal incisions were used to facilitate deliveries. Episiotomy became a routine practice well before research results were available to support it. Two Cochrane Reviews in 2009 and 2017 pointed out that restrictive use of episiotomy was associated with a lower risk of clinically relevant morbidities including posterior perineal trauma, need for suturing perineal trauma and healing complications. Carroli.G(2009),Jiang H(2017). Despite decades of research, which many interpret as having provided definitive evidence against the routine use of episiotomy, little professional consensus has been reached about the suitability of routine use. Pasc A,(2019)

Studies about the episiotomy rates, around the world, showed that this surgery ranged from 9.7\% (western) to 96.2\% (South America-Ecuador) with lowest episiotomy rates in English speaking countries and it remained high in South America, South Africa, and Asia. The rate of episiotomy varies between 8\% in Netherlands and 99\% in Eastern Europe. Asian women are likely to require episiotomy compared with non-Asian women as Asian skin tends not to stretch as well as Caucasians. Perineal trauma during vaginal delivery is very common occurring in about $40 \%$ of primi gravidae and $20 \%$ of multiparous women. In North America, report found that the episiotomy rate ranged from $6.7 \%$ to $22.9 \%$ in operative vaginal deliveries in 2016 and $14 \%$ in the UK. Graham, I et.al(2017), De-France CJ (2003), Van Limbeek S et al (2016) In developing countries such as Egypt, episiotomy is a common procedure to facilitate vaginal delivery. The World Health Organization (WHO)(2018) recommends an episiotomy rate of $10 \%$ for normal deliveries. Although the frequency of performing an episiotomy is decreasing, $30 \%$ to $50 \%$ of women may still receive episiotomy. There is a paucity of information regarding the frequency of episiotomy and associated factors at a national and regional level.

Fodstad K,et al (2014)

Morbidity associated with episiotomy may affect women's physical, psychological and social wellbeing, both in the immediate and long-term postnatal period. Women who experience perineal episiotomy can subsequently be affected by conditions such as dyspareunia, urinary and anal incontinence, perineal pain, and delayed mother-neonate interaction. Pain and discomfort related to have episiotomy been reported to interfere with women's daily activities postpartum, such as sitting, walking and lifting the baby. Priddis, H el.al,(2014)

Previous studies demonstrated that $97 \%$ and $71 \%$ of the primiparous women undergone episiotomy 
reported pain on the first and seventh postpartum days, respectively. Studies also revealed delayed perineal healing in women with episiotomy ; unhealed wound can prolong perineal pain which can exacerbate wound healing. Perineal pain resulting from episiotomy has always been a stressful problem for nulliparous women, which exerts a negative effect on their performance and first experience of becoming mother. The consequences of perineal pain include insomnia, fatigue, disturbance, anxiety, lack of attention to health education provided by caregivers, delay in joining the mother to her neonate (even sometimes prevention of emotional relationship between the mother and neonate), maternal immobility, formation of a sense of inability to look after the newborn, improper placement during breast-feeding, and in severe cases, deep vein thrombosis (Golezar, S.,et.al 2016, Apurva et al., 2016),

Many measures have been recommended to reduce perineal pain and improve wound haeling, such as observing the perineal hygiene, keeping the wound dry, and using various pharmacological and nonpharmacological treatments. The pharmacological treatments to alleviate perineal pain are acetaminophen, mefenamic acid, lidocaine gel, and sodium diclofenac suppository. The nurse should be aware of the effective treatment of episiotomy wound healing which can reduce the suffering of mothers and enhance healing. Steen,

\section{M.et.al,. (2016)}

Normal saline $(0.9 \%)$ is the favored wound cleansing solution because it is an isotonic solution and does not interfere with the normal healing process, damage tissue, cause sensitization or allergies or alter the normal bacterial flora of the skin (which would possibly allow the growth of more virulent organisms). Use of normal saline would be cost effective, easy to prepare, readily available and least damaging agent, as the healing occurs without local antibiotics or disinfectants. It does not alter the normal bacterial flora of the skin and has no effect on blood flow in capillaries. In addition it helps to remove things that can irritate the underlying tissue as well as help to wash out bacteria. It relieves redness and hastens the healing of episiotomy. Eduardo S,et.al. (2016), Attarha ,M. et. al( 2014). A comparative study to assess the effects of normal saline with other solution for wound cleansing. The study had 11 trials which included 310 postnatal mothers. The findings suggest that $62.9 \%$ of mothers treated with normal saline had good healing. The $38 \%$ of mothers treated with other solutions had got skin irritation. The result shown that normal saline is effective in reducing the infection rate than any other solutions. The study concluded that normal saline can be used as a healing agent which not interfere the normal healing process. Fernandez, R., Griffiths Russia (2012)

Furthermore Non-pharmacological treatments in this regard include cryotherapy, laser therapy, electrical stimulation, acupuncture, and pelvic floor exercises. Among the studies examining the effects of herbal medicines on wound healing and episiotomy pain based on the mean score of pain recovery, the use of lavender, olive, turmeric, cryotherapy and Aloe vera, were reported as the most effective methods in wound healing and alleviation of episiotomy pain . Delaram M et.al (2014), Shahrahmani H (2016). Aloe Vera is a medicinal plant from 1500 years BC in many countries, including Greece, China, Mexico, which had been traditionally used for centuries as a local medicine for various diseases and skin lesions. Aloe Vera is an herbaceous and perennial plant with long thick fleshy leaves that belongs to the Liliaceae family and is similar to cactus in appearance. Malek Hosseini A et al (2013) So far, 75 known compounds are found in Aloe Vera which contains 20 minerals, 20 amino acids, vitamins and water. Among them copper, iron, calcium, zinc, manganese, sodium, potassium, salicylic acid, vitamins A, B, C, E, B12 and folic acid can be pointed out. Sahu PK et.al (2013) 
In vitro studies and in studies that have been conducted on living organisms it has been shown that Aloe Vera inhibits thromboxane)an inhibitor of wound healing), helps healing and reduces inflammation . Magnesium lactate in Aloe Vera gel prevents the reaction of histamine, which causes itching and irritation to skin. Aloe Vera reduces the adhesion of leukocytes, increases the levels of IL-10 and decreases the levels of TNF alpha, so it is effective in inhibiting inflammatory reactions. Its regenerative property is related to a compound called Glucomannan which is rich in polysaccharides such as mannose that effects on receptors of the fibroblast growth factor and stimulates its activity and proliferation and increases collagen production. Aloe Vera gel not only increases the amount of collagen in wounds, but also changes the composition of collagen by increasing the collagen crosslinking and thereby accelerates healing of the wound. Tafazolie M.et.al(2010), Eghdampour, F.et.al. (2013)

Studies show that since $99 \%$ of Aloe Vera gel is water, it can increase the flexibility of skin and reduce its fragility Also, the muco-polysaccharides along with amino acids and zinc in Aloe Vera help skin integrity, retain its moisture, reduce erythema and help prevent skin ulcers Many studies have shown that using Aloe Vera to treat various wounds such as psoriasis, mouth ulcers, diabetic ulcers herpes and bed sores has had positive effects. Dat AD et al(2012)

Given that the care of episiotomy is one of the important and challenging issues in medicine and nursing and prevention of its complications is one of the main tasks of nurses which is also cost-effective, on the other hand, the use of traditional medicine and herbal plants is one of the ways to prevent episiotomy's side effect so this study intends to investigate the effect of Aloe Vera gel versus saline on pain relieve and healing process of episiotomy. Such information may be added to the nurses' evidence- based practices during postpartum care. Ultimately, this will improve puerperal women's health and positively influence maternal morbidity and mortality.

1.1 Aim of the study: the study aims to determine the effect of Aloe Vera gel versus saline on pain relieve and healing process of episiotomy

\subsection{Research Hypotheses:}

- Postnatal women who perform perineal wash with saline exhibit less perineal pain and more positive signs of episiotomy healing than those who do it with Aloe Vera Gel rubbing.

- Postnatal women who perform perineal rubbing with Aloe Vera Gel represent less perineal pain and more positive signs of episiotomy healing than those who do it with saline washing.

\section{MATERIALS AND METHOD}

\subsection{MATERIAL}

Research Design: A comparative quasi-experimental research design was utilized.

Setting: The study was carried out at the postnatal unit of EL-Shatby Maternity University Hospital in Alexandria. This particular setting was chosen because episiotomy is routinely performed to all primiparae attending for delivery.

Subjects: According to EL-Shatby Maternity University Hospital statistical center, 2017, flow rate of the laboring women undergo vaginal delivery were 1100 women at the end of December 2017. Ten percent of flow rate (110 women) was selected. Considering dropout during follow-up, the researchers added $10 \%$ from the 110 
women. Thus the total sample size was 120 parturient women; A convenience study subject of (120) women were selected from the previously mentioned setting according to the following inclusion criteria: primiparae immediately after childbirth, had a normal vaginal delivery with episiotomy, complaining of perineal discomfort (pain\}, does not use any pain relieving drug and free from diseases or health problems which may affect the healing process such as diabetes.

The selected subjects were equally divided into two experimental groups.

- Study group (1) included 60 women who were instructed to apply Aloe Vera Gel as local episiotomy treatment.

- Study group (2) comprised 60 women who were advised to irrigated episiotomy wounds with $0.9 \%$ normal saline solution in measured quantities

\section{Tools of data collection}

Four tools were used by the researchers to collect the necessary data:-

Tool I: Basic Data Structured Interview Schedule: It was developed by the researchers to collect the subject's socio-demographic characteristics such as: age, level of education, occupation...etc.

Tool II: Pain Intensity Visual Analogue Scale (VAS): It was adopted by Melzac and Ketz (1994) to assess the subjective level of pain severity over or near the wound site. It is a standardized linear scale that ranges from 0-10 corresponding to the degree of pain intensity. Where 0 indicates no pain and 10 indicates the worst pain. Scores 1, 2, 3 indicate mild pain, while 4, 5, 6 scores indicate moderate pain and finally 7, 8, 9 scores indicate severe pain.

Tool III: Wound Healing REEDA Scale: It was developed by Davidson,N(1974) and then reconstructed by Hill ,P (1990). This tool was used to assess the episiotomy healing process. It appraises the perineum for 5 healing signs: Redness, Edema, Ecchymosis, Discharge and Approximation. Thus the tool came to be known as REEDA scale. Each category is assessed and a number that ranged from 0 to 3 is assigned.

\section{Redness of the perineal area:}

$0=$ None

$1=$ within $0.25 \mathrm{~cm}$. of incision bilaterally (mild)

$2=$ within $0.5 \mathrm{~cm}$. of incision bilaterally (moderate)

$3=$ Beyond $0.5 \mathrm{~cm}$. of incision bilaterally (severe)

\section{Ecchymosis of the perineal area:}

$0=$ None

$1=$ within $.25 \mathrm{~cm}$. bilaterally or $0.5 \mathrm{~cm}$. unilaterally (mild)

$2=$ between 0.25 to $1 \mathrm{~cm}$. bilaterally or between 0.5 to 2

$\mathrm{cm}$. unilaterally (moderate)

$3=$ Greater than $1 \mathrm{~cm}$. bilaterally or $2 \mathrm{~cm}$. unilaterally

(severe)

Approximation of skin edges:

$0=$ Closed

$1=$ Skin separation $3 \mathrm{~mm}$. or less

$2=$ Skin and subcutaneous fat separation

$3=$ Skin, subcutaneous fat and fascial layer separation

\section{Tool IV: Bacteriological Wound Study}

Bacterial culture was taken from the episiotomy wound on the 5th postnatal day to assess the presence or absence of infection.

\section{Edema of the perineal area:}

$0=$ None

$1=$ Perineal, less than $1 \mathrm{~cm}$. from incision

(mild)

$2=$ Perineal and/or Vulvar, between 1 to $2 \mathrm{~cm}$. from incision (moderate)

$3=$ Perineal and/or Vulvar, greater than $2 \mathrm{~cm}$.

from incision (severe)

Discharge from the wound:

$0=$ None

$1=$ Serous

$2=$ Serosanguinous

$3=$ Bloody, purulent 


\subsection{METHOD}

2.2.1. Approval: Official letter clarifying the purpose of the study was obtained from the Faculty of Nursing and forwarded to the concerned personnel at El-Shatby Maternity University Hospital as an approval for data collection.

2.2.2. Tools development: Tool I was developed by the researchers after extensive review of recent and related literature while tool II and tool III were adopted. The content validity of the developed tools was tested by a jury of five expertise's' in the obstetrics and gynecological nursing to ascertain its relevance and completeness. Reliability of the tool (II and III) was assessed by using Cronbach's Alpha coefficient test. The tool consisted of relatively homogeneous items as indicated by the high reliability. Internal consistency of the tools were $0.7604 \& 0.8168$.

2.2.3. Aloe Vera fresh Gel was prepared by specialist, Prof. Dr. Salma Eldreer, Professor of plant \& microbiology, faculty of science. It was extracted from Natural cactus. The cactus leaf is placed longitudinally or vertically. Then cut the paper with the knife and strip the paper of liquid substances the resides on the first layer of the paper because it can cause obvious skin burns if applied directly to the skin, then scraped the Aloe Vera gel with a spoon. Place the gel in a sterilized, clean glass jar. It remains valid for use for a short period ranging from one to four weeks in the refrigerator. He provided the researchers with a certificate for insurance of safety use of Gel.

2.2.4. Pilot study: A pilot study was carried out on 12 women (who were excluded from the sample) to ascertain the clarity and the applicability of the tools then the necessary changes were undertaken.

2.2.5. Selection of the study subjects: The researchers selected the women who fulfilled the criteria from the postnatal unit of EL-Shatby Maternity University Hospital in Alexandria. The researchers explained the purpose of the study to every woman, and then her consent to participate in the study was obtained. Each interview was conducted individually and in total privacy to assure that information to be obtained will be confidential and will be used only for research purposes.

2.2.6. Procedure of the study: The study proceeded as follows:

- All study subjects were individually interviewed by the researchers within 4-6 hours after childbirth to collect the basic data (tool I), episiotomy pain intensity (tool II), as well as to assess the episiotomy wound (tool III). After the assessment the researchers did perform perineal care for each subject. Then the researchers applied the two methods (Aloe Vera gel , and Normal saline ) of treatments :

- For study group (1) the researchers rubbed (3cc or 1teaspoons) of Aloe Vera gel for the first time on episiotomy area by disposable glove for training and according to given training, the mother continued using gel every 12 hours. Adequate supply of " Aloe Vera Gel put in a sterilized, clean glass jar "' for used it twice per day over ten days was provided.

- For study group (2) the researchers irrigated episiotomy wounds with $0.9 \%$ normal saline solution (10 $\mathrm{cm}$ ) for the first time on episiotomy area from forchette to anus by disposable syringe for training and according to given training, the mother continued using normal saline every 12 hours. Adequate supply of $0.9 \%$ normal saline $(10 \mathrm{~cm}$ at each time) for used it twice per day over ten days was provided.

- After washing the area was dried and then a clean dry pad was applied by the woman. 
- After the procedure each study subject was asked to re-demonstrate the previously mentioned procedure at home two times per day until the tenth postpartum day.

- Follow up: Women of the two groups were instructed to come to the hospital for follow up visits during the morning shift on the $5^{\text {th }}$, and $10^{\text {th }}$ day post-partum, the perineal area was observed for (redness, edema, ecchymosis, approximation of the skin and pain

- On the fifth day each study subject came to the hospital during the morning shift.

- $\quad$ The researchers had evaluated the episiotomy pain intensity (tool II) and episiotomy wound healing (tool III).

- Then the researchers had taken a bacteriological culture through the following procedure:-

- A sterile glove was applied. Then wound was irrigated thoroughly with a sterile saline solution.

- A sterile swab from a culture collection kit was pressed to the wound with enough pressure to press out fluid from the wound tissue. While gently twirled the swab between the fingers, it was moved from one edge of the wound to the other edge in a zigzag motion. Culture collection/transport kit was labeled with name, date and time of culture.

- $\quad$ Then the swab was immediately transported in the culture medium to the microbiology lab at El Shatby hospital for culturing as quickly as possible.

- On the tenth day each study subject again came to the hospital during the morning shift. The researchers had repeated what occurred in the first visit except performing wound culture.

- The healing process of the episiotomy was assessed and compared among the two study groups to find out the most effective method in dealing with the episiotomy wound.

2.2.7. Handling and analysis of data: The raw data were coded and transformed into coding sheets. The results were checked. Then, the data were entered into SPSS system files (SPSS package version 11) using personal computer. Output drafts were checked against the revised coded data for typing and spelling mistakes. Finally, analysis and interpretation of data were conducted. The following statistical measures were used:

- Descriptive statistics including frequency, distribution, mean, and standard deviation were used to describe different characteristics.

- Kolmogorov - Smirnov test was used to examine the normality of data distribution.

- Univariate analyses including: t-test was used to test the significance of results of quantitative variables. Moreover, Chi-Square test, Fisher's Exact test, Monte Carlo test, Marginal Homogeinty test and McNemar test were used to test for significance among qualitative variables.

- The significance of the results was at the $5 \%$ level of significance.

2.2.8. Ethical consideration: for each recruited subject the following issues will be considered: securing the subject's informed written consent after explanation of research purpose, keep anonymity, privacy and right to withdraw at any time as well as assuring confidentiality of the collected data. 


\section{RESULTS}

According to table (I) the socio-demographic characteristics of both groups were more or less similar without any statistically significant differences. Where, only $20 \%$ of both groups were in their thirties. Again about two-fifths (43.3\%) of each group were secondary school graduates. Almost all of the Aloe Vera (93.3\%) and normal saline (90\%) groups were housewives. However, only 3.3\% of Aloe Vera Gel group compared to as much as $16.7 \%$ of normal saline were rural residents. The percent of subjects from extended families among the Aloe Vera Gel group 43.3\% almost double-folded that among the normal saline group $23.3 \%$.

Table (I): Number \& Percent Distribution of The Study Subjects according to Their Socio-demographic Characteristics

\begin{tabular}{|c|c|c|c|c|c|}
\hline \multirow[t]{2}{*}{ Subject's Socio-demographic Characteristics } & \multicolumn{2}{|c|}{$\begin{array}{c}\text { Aloe Vera } \\
(\mathrm{no}=\mathbf{6 0})\end{array}$} & \multicolumn{2}{|c|}{ Normal Saline $(n o=60)$} & \multirow[t]{2}{*}{ Significance } \\
\hline & No & $\%$ & No & $\%$ & \\
\hline $\begin{array}{ll} & \text { Age } \\
\text { - } & <20 \\
\text { - } & 20- \\
\text { - } & 30 \text { to }<40\end{array}$ & $\begin{array}{c}4 \\
44 \\
12\end{array}$ & $\begin{array}{c}6.70 \\
73.30 \\
20.00\end{array}$ & $\begin{array}{l}10 \\
38 \\
12\end{array}$ & $\begin{array}{l}16.70 \\
63.30 \\
20.00\end{array}$ & \multirow[t]{2}{*}{$\begin{array}{c}\mathrm{t}=0.71 \\
\mathrm{p}=0.498\end{array}$} \\
\hline Mean \pm SD & \multicolumn{2}{|c|}{$25.10 \pm 5.20$} & \multicolumn{2}{|c|}{$24.4 \pm 5.00$} & \\
\hline $\begin{array}{ll}\text { o } & \text { Level of education } \\
\text { - } & \text { Illiterate / read \& write } \\
\text { - } & \text { Primary/preparatory school } \\
\text { - } & \text { Secondary school } \\
\text { - } & \text { University } \\
\end{array}$ & $\begin{array}{c}10 \\
20 \\
26 \\
4\end{array}$ & $\begin{array}{r}16.70 \\
33.30 \\
43.30 \\
6.70\end{array}$ & $\begin{array}{c}12 \\
6 \\
26 \\
16\end{array}$ & $\begin{array}{l}20.00 \\
10.00 \\
43.30 \\
26.70\end{array}$ & $\begin{array}{c}X^{2}=1.31 \\
P 0.75\end{array}$ \\
\hline $\begin{array}{ll}\text { - } & \text { Occupation } \\
\text { - } & \text { Worker } \\
\text { - } & \text { Employee } \\
\text { - } & \text { House wife }\end{array}$ & $\begin{array}{c}0 \\
4 \\
56\end{array}$ & $\begin{array}{c}0.00 \\
6.70 \\
93.30\end{array}$ & $\begin{array}{c}2 \\
4 \\
54\end{array}$ & $\begin{array}{c}3.30 \\
6.70 \\
90.00\end{array}$ & ${ }^{\mathrm{MC}} \mathrm{P}=0.834$ \\
\hline $\begin{array}{cl} & \text { Current residence } \\
\text { - } & \text { Rural } \\
\text { - } & \text { Urban }\end{array}$ & $\begin{array}{c}2 \\
58\end{array}$ & $\begin{array}{c}3.30 \\
96.70\end{array}$ & $\begin{array}{l}10 \\
50\end{array}$ & $\begin{array}{l}16.70 \\
83.30\end{array}$ & ${ }^{\mathrm{FET}} \mathrm{P}=0.149$ \\
\hline $\begin{array}{cc}\text { - } & \text { Type of family } \\
\text { - } & \text { Nuclear } \\
\text { Extended }\end{array}$ & $\begin{array}{l}34 \\
26\end{array}$ & $\begin{array}{l}56.70 \\
43.30\end{array}$ & $\begin{array}{l}46 \\
14\end{array}$ & $\begin{array}{l}76.70 \\
23.30\end{array}$ & $\begin{array}{l}X^{2}=3.4 \\
P=0.06\end{array}$ \\
\hline
\end{tabular}

Table (II) exhibits a comparison between perineal pain intensity between Aloe Vera group and normal saline group overtime. Before Intervention "during the first 24 postnatal hours, there is no a statistically significant difference between both groups regarding perineal pain intensity within 24 hours after delivery. Where, about two-fifths (45\%-48.3\%) of Aloe Vera and normal saline groups, respectively, had mild perineal pain. Almost equal proportions $(23.3 \%, 26.7 \%)$ of Aloe Vera and the normal saline group did exhibit moderate perineal pain. Equal proportions $(31.7 \%, 25 \%)$ of Aloe Vera and the normal saline group did suffer from severe pain. On $5^{\text {th }}$ postnatal day, more than one- half (55\%) of the Aloe Vera group had mild pain compared to only $36.7 \%$ of 
normal saline group. More than two-fifths $(45 \%)$ of the Aloe Vera gel group did suffer from moderate perineal pain compared to more than one half $(55 \%)$ of normal saline group. No one $(0.00 \%)$ of Aloe Vera group did report sever pain compared to more than one-tenth $(11.7 \%)$ of normal saline group. There was a statistically significant differences between both groups on $5^{\text {th }}$ postpartum day as regards perineal redness $(\mathrm{P}=0.0087)$. However on the $10^{\text {th }}$ postpartum day, it was observed that the majority $(83.3 \%)$ of Aloe Vera group had mild perineal pain compared to only $68.3 \%$ of normal Saline group. Again only $16.7 \%$ of Aloe Vera group did experience moderate pain compared to about one third (31.7\%) of normal saline group. There was a statistically significant differences between both groups in relation to perineal pain intensity after 10 postnatal days $\left(\mathrm{X}^{2}=6.136, \mathrm{p}=0.046\right)$.

Table (II) Number \& Percent Distribution of perineal pain intensity between Aloe Vera group and normal saline group overtime

\begin{tabular}{|c|c|c|c|c|c|c|c|c|c|}
\hline \multirow{4}{*}{$\begin{array}{l}\text { Perineal pain } \\
\text { intensity }\end{array}$} & \multirow{2}{*}{\multicolumn{2}{|c|}{$\begin{array}{l}\text { Before intervention } \\
\text { Within } 24 \text { hours }\end{array}$}} & & \multicolumn{6}{|c|}{ After intervention } \\
\hline & & & \multirow{3}{*}{ Sig, } & \multicolumn{2}{|c|}{ On $5^{\text {th }}$ day } & \multirow{3}{*}{ Sig, } & \multicolumn{2}{|c|}{ On $10^{\text {th }}$ day } & \multirow{3}{*}{ Sig, } \\
\hline & $\begin{array}{c}\text { Aloe } \\
\text { Vera } \\
(\text { no= }=60)\end{array}$ & $\begin{array}{c}\text { Normal } \\
\text { Saline } \\
(\text { no }=60)\end{array}$ & & $\begin{array}{c}\text { Aloe } \\
\text { Vera }(n=60)\end{array}$ & $\begin{array}{c}\begin{array}{c}\text { Normal } \\
\text { Saline } \\
(\text { no }=60)\end{array} \\
\end{array}$ & & $\begin{array}{c}\text { Aloe } \\
\text { Vera } \\
(\text { no }=60)\end{array}$ & $\begin{array}{c}\text { Normal } \\
\text { Saline } \\
(\text { no }=60)\end{array}$ & \\
\hline & $\%$ & $\%$ & & $\%$ & $\%$ & & $\%$ & $\%$ & \\
\hline Mild & 45.00 & 48.3 & $\begin{array}{l}X^{2}=0.614 \\
P=0.735\end{array}$ & 55.00 & 36.7 & $\mathrm{X}^{2}=9.476$ & 83.3 & 68.30 & $\begin{array}{c}X^{2}= \\
6.136\end{array}$ \\
\hline Moderate & 23.3 & 26.70 & & 45.00 & 51.7 & $\mathrm{P}=0.0087^{*}$ & 16.7 & 31.70 & $\begin{array}{c}\mathrm{P}= \\
0.046\end{array}$ \\
\hline Severe & 31.7 & 25.00 & & 0.00 & 11.6 & & 0.00 & 0.00 & \\
\hline
\end{tabular}

*significant at $\mathbf{P} \leq \mathbf{0 . 0 5}$

\section{$\mathrm{X}^{2}$ : chi-square test}

Table (III) clarifies the comparison of REEDA assessment between Aloe Vera and normal saline groups overtime. There is no a statistically significant difference between the REEDA assessment among both groups during the first 24 postnatal hours. About two-fifths (46.7\%-43.3\%) of Aloe Vera and saline groups, respectively, had moderate perineal redness around the incision line of episiotomy. A similar proportion (36.7\%) in both groups had moderate edema of the perineal area. All subjects in both groups had closed suture line and no any wound discharge.

On the $5^{\text {th }}$ postnatal day the majority $(83.3 \%)$ of the Aloe Vera gel group had mild redness of perineal area compared to only $56.7 \%$ of normal saline group. Meanwhile mild edema was observed among one-third $(33.3 \%)$ of Aloe Vera group compared to more than one-half (56.7\%) of normal saline group. More than threefifths $(63.3 \%)$ of the Aloe Vera gel group had serum discharge from the episiotomy incision wound compared to $40 \%$ of normal saline group. Whereas, closed episiotomy incision wound was observed in approximate one-half $(46.7 \%)$ of Aloe Vera group compared to only one-tenth $(10 \%)$ of the normal saline group. There was a statistically significant differences between both groups on $5^{\text {th }}$ postpartum day as regards perineal redness ( $\left.{ }^{\mathrm{MC}} \mathrm{P}=0.005\right)$, edema of perineal area $\left({ }^{\mathrm{MC}} \mathrm{P}=0.005\right)$, type of discharge $\left({ }^{\mathrm{MC}} \mathrm{P}<0.0001\right)$, and approximation of skin

$$
\text { edges }\left({ }^{\mathrm{MC}} \mathrm{P}=0.002\right) \quad \text { On } 10^{\text {th }} \text { postnatal day as much as } 63.3 \% \text { of the Aloe Vera gel group }
$$
compared to only $6.7 \%$ of the normal saline group had no redness of the perineal area. There was a statistically 
significant differences between the both groups $\left({ }^{\mathrm{MC}} \mathrm{P}<0.0001\right)$ in this respect. Again, on the $10^{\text {th }}$ postnatal day perineal edema was absent among all Aloe Vera group compared to two-fifths (40\%) of normal saline group. About two-thirds (63.3\%) of Aloe Vera group had serum discharge compared to only $6.7 \%$ of normal saline group. There was a statistically significant difference between both groups regarding the presence of perineal edema ( ${ }^{\mathrm{MC}} \mathrm{P}<0.0001$ ), type of discharge from episiotomy wound $\left({ }^{\mathrm{MC}} \mathrm{P}<0.003\right)$. Regarding approximation of skin edges, about two-thirds (63.3\%) of the Aloe Vera group had closed wound edges compared to only $16.7 \%$ of the normal saline group. There was also a statistically significant difference between both groups in this respect $\left({ }^{\mathrm{MC}} \mathrm{P}=0.001\right)$.

\section{Table (III): Number \&Percent Distribution of the Study Subjects According To Their REEDAAssessment} over Time

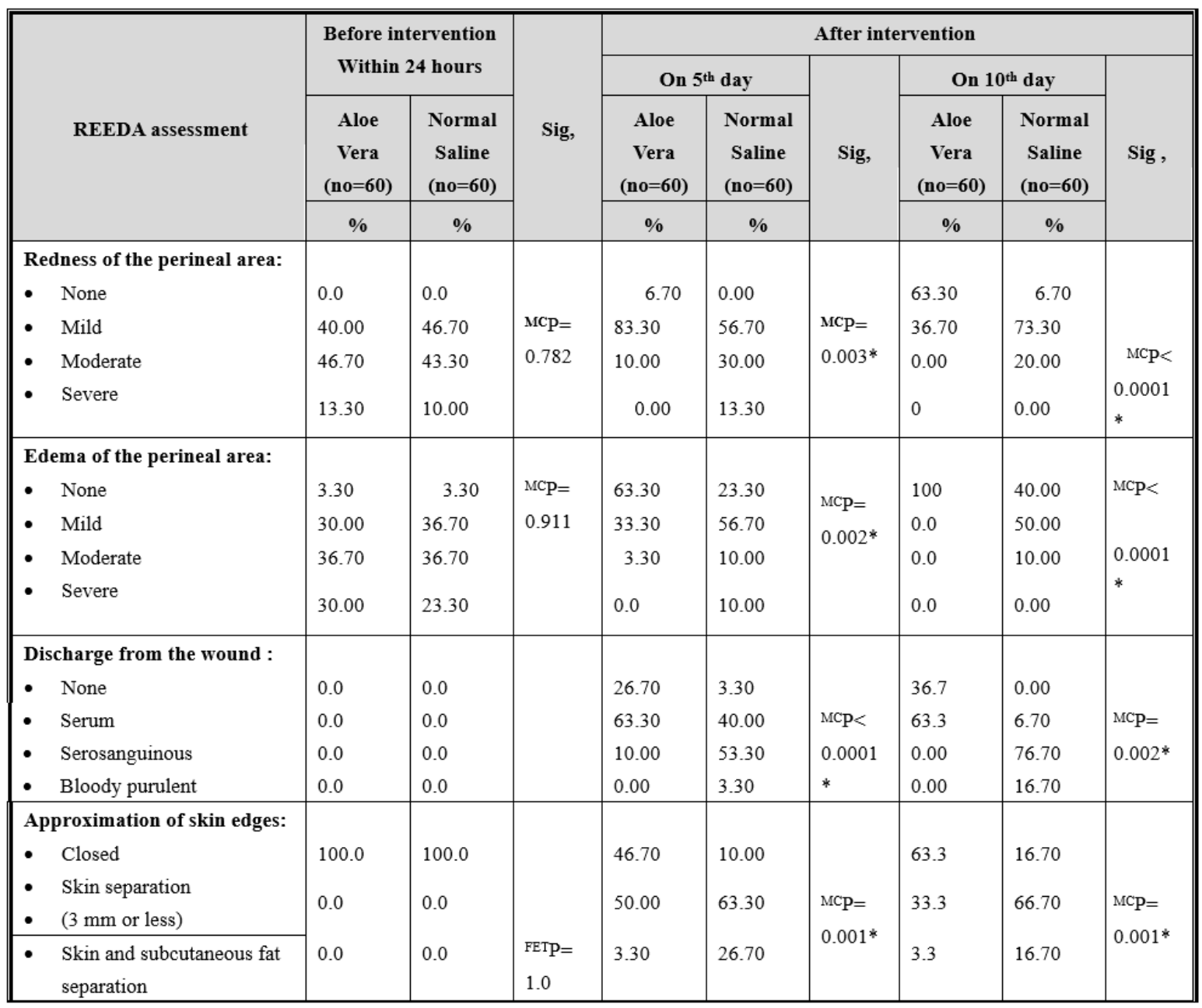

${ }^{M C}$ P: Monte Carlo test

Table (IV) represents number \& percent distribution of the study subjects in the two groups according to their perineal healing scores on $5^{\text {th }}$ and $10^{\text {th }}$ postpartum period. On the $5^{\text {th }}$ postnatal day more than three-quarters $(86.7 \%)$ of Aloe Vera group had complete healing of episiotomy wound compared to only $36.7 \%$ of the normal 
saline group. Meanwhile only $13.3 \%$ of Aloe Vera group had partial healing compared to more than $53.3 \%$ of the normal saline group. There was a statistically significant difference between both groups regarding perineal healing scores $(\mathrm{p}<0.0001)$ during the $5^{\text {th }}$ postnatal days. On the $10^{\text {th }}$ postpartum day, all of the Aloe Vera group did achieve complete healing of episiotomy wound compared to $80 \%$ of the normal saline group. There was a statistically significant difference between both groups $(\mathrm{p}<0.0001)$

Table (IV): Number \&Percent Distribution Of The Study Subjects According To Their Perineal Healing Scores On $5^{\text {th }}$ And $1^{\text {th }}$ Postpartum Day

\begin{tabular}{|c|c|c|c|c|c|c|c|c|c|c|}
\hline \multirow{4}{*}{ Perineal Healing Scores } & \multicolumn{9}{|c|}{ After intervention } & \multirow{4}{*}{ Sig } \\
\hline & \multicolumn{4}{|c|}{ On $5^{\text {th }}$ day } & \multirow{3}{*}{ Sig, } & \multicolumn{4}{|c|}{ On $10^{\text {th }}$ day } & \\
\hline & \multicolumn{2}{|c|}{$\begin{array}{c}\text { Aloe Vera } \\
(\text { no }=60)\end{array}$} & \multicolumn{2}{|c|}{$\begin{array}{c}\text { Normal Saline } \\
(\mathrm{no}=60)\end{array}$} & & \multicolumn{2}{|c|}{$\begin{array}{l}\text { Aloe Vera } \\
(\mathrm{no}=60)\end{array}$} & \multicolumn{2}{|c|}{$\begin{array}{c}\text { Normal Saline } \\
(\mathrm{no}=60)\end{array}$} & \\
\hline & no & $\%$ & no & $\%$ & & No & $\%$ & No & $\%$ & \\
\hline -Complete healing $<5$ & 52 & 86.70 & 22 & 36.70 & \multirow{5}{*}{$\begin{array}{l}\mathrm{t}=4.96 \\
\mathrm{p}= \\
<0.001 *\end{array}$} & 60 & 100 & 48 & 80 & \multirow{5}{*}{$\begin{array}{r}\mathrm{t}=6.96 \\
\mathrm{P}<0.0001 *\end{array}$} \\
\hline -Partial healing $5<10$ & 8 & 13.30 & 32 & 53.30 & & 0.0 & 0.0 & 12 & 20 & \\
\hline -Non healing $10-15$ & 0 & 0.00 & 6 & 10.00 & & 0.0 & 0.0 & 0 & 0.0 & \\
\hline Min-Max & \multicolumn{2}{|c|}{$2-10$} & \multirow{2}{*}{\multicolumn{2}{|c|}{$1-6$}} & & \multicolumn{2}{|c|}{$1-8$} & \multicolumn{2}{|c|}{$0-4$} & \\
\hline Mean \pm SD & \multicolumn{2}{|c|}{$5.4 \pm 2.2$} & & & & \multicolumn{2}{|c|}{$3.9 \pm 1.8$} & \multicolumn{2}{|c|}{$1.4 \pm 1.2$} & \\
\hline
\end{tabular}

Table (V) exhibits the number \& percent distribution of isolated organisms among the study subjects on the $5^{\text {th }}$ postnatal day. It is obvious that abundant growth of isolated organisms was observed among more than one-fifth $(26.7 \%)$ of the Aloe Vera group compared to two-thirds $(66.7 \%)$ of normal saline group. While moderate growth of isolated organisms was equally distributed (33.3\%) among the both groups. There was a statistically significant difference between both groups regarding count of isolated organisms $(\mathrm{p}<0.0001)$.

The same table also shows that candida was observed among $60 \%$ of the Aloe Vera group compared to $100 \%$ of the normal saline group. Lactose fermenting colonies (Gram negative cocci) was also observed among $80 \%$ of the Aloe Vera group compared to almost all $(96.7 \%)$ of the normal saline group. While staphylococcus aureus (gram positive cooci) was observed among $43.3 \%$ of the Aloe Vera group compared to $100 \%$ of the normal saline group. There was a statistically significant difference between both groups in relation to types of isolated organisms $(\mathrm{p}<0.0001, \mathrm{FEP}=0.013, \mathrm{p}<0.0001$, respectively $)$ 
Table (V): Number \&percent distribution of isolated organisms among the study subjects on the $5^{\text {th }}$ postnatal day

\begin{tabular}{|c|c|c|c|c|c|}
\hline \multirow[t]{2}{*}{ Isolated organisms } & \multicolumn{2}{|c|}{$\begin{array}{c}\text { Aloe Vera } \\
(n o=60)\end{array}$} & \multicolumn{2}{|c|}{$\begin{array}{c}\text { Saline } \\
(n o=60)\end{array}$} & \multirow[t]{2}{*}{ Significance } \\
\hline & No & $\%$ & No & $\%$ & \\
\hline \multirow{4}{*}{$\begin{array}{ll}\text { Count of isolated organisms } \\
\text { - } & \text { Abundant growth }+++ \\
\text { - } & \text { Moderate growth }++ \\
\text { - } & \text { Few growth }+ \\
\end{array}$} & & & & & \multirow{4}{*}{$\begin{array}{l}X^{2}=19.2 \\
P<0.0001 *\end{array}$} \\
\hline & 16 & 26.70 & 40 & 66.70 & \\
\hline & 20 & 33.30 & 20 & 33.30 & \\
\hline & 24 & 40.00 & 0.0 & 0.0 & \\
\hline \multirow{3}{*}{$\begin{array}{l}\text { Type of isolated organisms\# } \\
\text { - } \quad \text { Candida } \\
\text { - } \\
\text { Gram negative organisms } \\
-\quad \text { Lactose fermenting colonies } \\
\text { - } \quad \text { Non Lactose fermenting colonies } \\
\end{array}$} & 36 & 60.00 & 60 & 100 & $\begin{array}{l}\mathrm{X}^{2}=11.2 \\
\mathrm{P}=0.001^{*}\end{array}$ \\
\hline & 48 & 80.00 & 58 & 96.7 & $\mathrm{FEP}=0.031 *$ \\
\hline & 38 & 63.30 & 50 & 83.3 & $\mathrm{X}^{2}=3.92 \quad \mathrm{P}=0.021^{*}$ \\
\hline \multirow{3}{*}{$\begin{array}{ll}\text { - } & \text { Gram positive organisms } \\
- & \text { Staphylococcus aureus } \\
- & \text { Staphylococcus epidemides } \\
\end{array}$} & & & & & \multirow{2}{*}{$\mathrm{X}^{2}=4.11 \quad \mathrm{P}=0.003 *$} \\
\hline & 26 & 43.3 & 60 & 100 & \\
\hline & 42 & 70 & 60 & 100 & $\mathrm{FEP}=0.016^{*}$ \\
\hline
\end{tabular}

\section{Discussion}

Childbirth has been found to be an overpowering experience in a woman's life since ancient times. It is a physical occasion and a strong enthusiasm in a woman's life when she progresses to parenting. Postpartum period becomes a more challenging period as chances of genital region injury in an outcome of childbirth which requires special attention for her wellbeing. Perineal pain and discomforts during early puerperium are the most common causes of morbidity affecting functions and experience of early motherhood. Intervention toward the goal of alleviating or relieving woman pain and the discomfort it causes are primarily nursing functions. Concerning postpartum episiotomy pain some women choose not to use pain killing medications at all or to use it infrequently for various reasons, therefore, alternative methods to control pain and relieve postpartum discomfort need to be available to such women. Recently utilization of alternative \& complementary therapies by utilizing essential oils such as lavender, olive, turmeric, Aloe Vera, were reported as the less costs, most effective methods in wound healing and attenuation of episiotomy pain. Mahmoodi, F,et.al ( 2015)Hence the present study was conducted to evaluate the effect of Aloe Vera versus normal saline on episiotomy healing.

Perineal pain resulting from episiotomy has always been a stressful problem for nulliparous women, which put forth a negative consequence on their recital. Abedian, Z. et.al (2018). The present study proved that perineal pain was obvious among both the Aloe Vera and normal saline groups. There were a statistically significant differences between both groups about perineal pain intensity on $5^{\text {th }}$ and $10^{\text {th }}$ postnatal days $(p$ $=0.0087,0.046)$. This finding may be attributed due to the presence of carboxy peptidase in Aloe Vera which inactivates bradykinin which is the powerful factor of acute inflammatory pain. Magnesium lactate in Aloe Vera gel is used as anti-itching and analgesic drug by inhibiting histidinedecarboxylase which controls conversion of histidine to histamine in mast cells. Yagi, A .et.al (2003), Maenthaisong, R,. et al (2007)

One research is available in harmony with the current study by Nazari et al (2019) who carried out a study "to evaluate the effect of Aloe Vera gel on perineal pain and wound healing after episiotomy among primiparous women in Iran ". They concluded that the use of Aloe Vera gel, compared to a normal saline solution, reduces pain and accelerates healing of vulvar ulcers without side effects. However, this finding is somewhat in line with 
several studies regarding the application of Aloe Vera gel. First, Varaei et al (2017) who had study titled the effect of Aloe Vera gel and Nitrofurazone on dressing related pain of superficial burn wounds in Iran. They reported that dressing pain intensity decreased significantly during a 72-hour period in both areas $(\mathrm{p}=0.001)$, but Aloe vera gel could reduce pain more and faster than nitrofurazone. Second, a study was done by Alamolhoda H et al (2014) about "Effects of Aloe Vera gel on breast fissures in breastfeeding women in Iran. They concluded that Aloe Vera gel can improve breast fissures. Third, a study conducted by Sabzaligol,M. et al,(2014) who conducted a randomized controlled clinical trial to assess the effect of Aloe Vera gel on perineal pain \& wound healing after episiotomy in Iran. They concluded that Aloe Vera gel alleviated the perineal pain after episiotomy. Fourth, Eshghi F, et.al (2010). They had investigated effects of Aloe Vera Cream on Post hemorrhoidectomy pain and wound their results had indicated that patients in the topical group had significantly less post-operative pain at hours $12,24,48$ hrs post-surgery $(\mathrm{p}<0.001)$. Wound healing at the end of second postoperative week was significantly greater in Aloe Vera group compared with placebo group $(\mathrm{p}<0.001)$.Patients needed fewer analgesics post operatively $(\mathrm{p}<0.001)$. The study concluded that application of Aloe Vera cream on the surgical site is effective in reducing postoperative pain

The present study indicated that a statistically significant difference was observed in episiotomy healing using REEDA scale among study group 1(Aloe Vera) and study group2 (normal saline) after application, where (P 0.001) .The finding of this study indicated that perineal healing has improved significantly in favorite of Aloe Vera gel among the study group1, where maximum relief of perineal healing, ecchymosis, pain, edema, and redness accomplished among these women on day 10 . This is could be explained by the fact that the best-known active components of Aloe Vera gel can hinder thromboxane (an inhibitor of wound healing), progress the wound healing process, and lessen inflammation. Actually, glucomannan and plant growth harmone gibberellins interacts with growth factor receptors of fibrobroblast and stimulate its activity and proliferation for increases collagen synthesis in topical and oral administration of Aloe Vera. The Aloe administration also influence collagen composition (more type III) and increased collagen cross linking for wound contraction and improving breaking strength. It also increases synthesis of hyaluronic acid and dermatan sulfate in the granulation tissue of a healing wound. Magnesium lactate available in the gel can prevent the production of histamine that causes itching and irritation of the skin. Somboonwong, J. et al (2000), Hayes, SM (1999, Reynolds, T(1999) Consequently, such results could be added to the rational of using Aloe Vera Gel for healing. Furthermore, it draws the attention for the need for more researches to be added to the evidence - based background for such practice

This result is in accordance with the previously mentioned study. Nazari et al (2019). They concluded that the use of Aloe Vera gel, compared to a normal saline solution accelerates healing of vulvar ulcers without side effects; therefore, it can be beneficial to women. However, this finding is somewhat in line with at least five other researches regarding the application of Aloe Vera gel. First, Pooja et al.(2018) who carried out an experimental study "to evaluate the effectiveness of aloe Vera gel application on episiotomy wound healing among mothers in early Postpartum period "They have proven that the application of Aloe Vera Gel was an important and effective intervention in improving healing of episiotomy in early maternal postpartum. Second, Koli $\mathbf{P}$ et al.(2018) who carried out an experimental study "To Evaluate the Effectiveness of Aloe Vera gel application on episiotomy wound healing among mothers in early Postpartum period in Rajasthan. They have 
proven that the application of Aloe Vera gel was an important and effective intervention in improving healing of episiotomy in early maternal puerperium. Third, the previously mentioned study done by Sabzaligol.M.et.al,(2014) . They had concluded that Aloe Vera gel improved the rate of wound healing in episiotomy. Fourth, Malazem et al (2014) who had done a randomized controlled trial on 90 women undergoing a cesarean section to investigate the Aloe Vera Gel and Cesarean in Iran. They reported that the application of Aloe Vera gel was efficient in a cesarean wound healing. Fifth Eghdampour ,F et al.(2013) who conducted an experimental research on 74 women underwent nulliparous episiotomy to assess "the effect of Aloe Vera and Calendula on perineal healing after episiotomy in primiparous women in Iran. They had stated that using Aloe Vera and Calendula ointment significantly increases the rate of episiotomy wound healing so it can be used to accelerating the episiotomy healing.

Until now, a large number of studies have been conducted on Aloe Vera gel as anti-inflammatory, skin protection, anti-tumor anti-bacterial, anti-diabetic, anti-viral, antiseptic, and wound healer. It is used to treat wounds such as mouth sores, psoriasis, wounds. Sahu et al (2013), Malek HA (2013). These also proved the results of this study. In most of the studies, Aloe Vera gel was used in form of a processed product, such as gel or cream. Dat ,AD.et.al (2012), Eshghi, F .et al (2010). In this study, the fresh natural gel was used to preserve its effective substances. This study is incongruent with some researchers have stated that some of the effective substances of Aloe Vera gel are wasted in the process of preparation and conservation. Sahu et al (2013)

In addition, the current finding is relatively in harmony with the study of Tafazolie, M et al (2010) who conducted study about " the impact of Aloe Vera gel and Lanolin ointment on treating the nipple fissure, where they found that Aloe vera gel is more effective than Lanolin ointment in treating the nipple fissure.

It is interesting to notice that the application of saline - in the present study - had slow improvement of episiotomy healing. On the 5th postnatal day only $36.7 \%$ among saline group had complete healing of episiotomy wound. Meanwhile more than one half 53.3\% of the saline group had partial healing. This result is in line with Makvandi S et.al (2014) who studied the effect of local Gentamicin solution on episiotomy healing: a randomized controlled clinical trial in Iran. They concluded that Gentamicin solution has a significant effect an earlier and faster healing of episiotomy wound than normal saline. On the other hand, the same results contradict with the findings of two studies. First the Egyptian study done Gomaa $\mathbf{R}$ et al (2019) tilted the effectiveness of Betadine versus normal saline dressing on episiotomy wound healing. They concluded that normal saline had a positive effect on the healing of episiotomy wound among postnatal mothers in form of lower REEDA scale score and pain scores (VAS). Second an Iranian study done by Attarha M et.al (2014) that compared normal saline with povidon iodine solution on episiotomy in nulliparous. They found that on 10th day in saline group mean of ecchymosis and discharge $[0.36( \pm 0.52), 0.36( \pm 0.56)]$ was more than control group $[0 / 16( \pm 37), 0.1( \pm 0 / 36)](\mathrm{P}<0.02,0.007)$ respectively. Normal saline can be replaced with povidon iodine solution in episiotomy care.

In addition, complications of episiotomies include accidental extension into the anal sphincter or rectum, damage to the Bartholin's gland, unsatisfactory anatomic results such as skin tags, asymmetry or excessive narrowing of the introitus. Other complications include pain and oedema, increased blood loss, haematoma, infection and dehiscence. Infection is the invasion of the host by microorganisms, which then multiply in close association with the host's tissues. Bacteria can cause a multitude of different infections, ranging in severity from 
in apparent to fulminating. Howard, D et.al (1999), Zetterstrom et al (1999)

So far, the present study revealed that the growth of isolated organisms was much less among the Aloe Vera group. This result was somewhat similar to on Heggers $\mathbf{J} \mathbf{P}$ et al. (1995). They did a study about wound healing effects of Aloe Vera gel and other topical antibacterial agents in rat skin. They suggested that Aloe Vera can enhance wound healing process by eliminating bacteria which causes inflammation. Aloe Vera gel was bactericidal against Pseudomonas aeruginosa and acemannan prevented it from adhering to human lung epithelial cells in a monolayer culture, a processed Aloe Vera gel preparation inhibited the growth of fungus Candida albicans, (Stanley,MC.et.al (2014) ,Kumar,N.et.al (2015), Rezazadeh, F et.al (2016). The antiseptic property of Aloe Vera is due to presence of six antiseptic agents namely lupeol, salicylic acid, urea nitrogen, cinnamonic acid, phenols and sulphur. These compounds have inhibitory action on fungi, bacteria and viruses, (Qian,Y. et.al(2015), Anjum.S et.al(2016).

Finally, the results of the present study reveals that the two methods for treatment of perineal discomforts namely (Aloe Vera \& normal saline) have eventually lead to recovery and relief of signs and symptoms of perineal discomforts and perineal pain. However, Aloe Vera has achieved recovery faster and earlier than normal saline. In addition, Aloe Vera possesses several other properties which probably make it better and safer treatment of choice. It is natural, available, easy to use, less expensive and with minimal adverse effect on the mother.

\section{CONCLUSION and RECOMMENDATIONS}

\subsection{CONCLUSION}

Based on the study findings, it could be concluded that the application of Aloe Vera gel was more effective on wound healing and perineal pain than Saline among postnatal women with episiotomy. Moreover the growth of the isolated organisms among the episiotomy wound treated with the Aloe Vera gel were less than among those treated with Saline.

\subsection{RECOMMENDATIONS}

Based on the findings of the present study the following recommendations are suggested:

1. The curricula of basic nursing / midwifery education as well as continuing education could be enriched with , correct , relevant evidence - based information about non-pharmacological management of episiotomy with essential oils.

2. In -service training programs for nurses in postpartum units- about the utilization of non- pharmacological approaches is recommended

3. Further researches are also recommended:

- The effect of Aloe Vera gel on other pains encountered during the reproductive life.

- Assessment of postnatal women's satisfaction with the use of non- pharmacological techniques for management of episiotomy pain and healing

- $\quad$ Replication of the present study at different sittings and among different subjects. 


\section{References}

Abedian, Z., Nezhad ,M N., Asili , J., Esmaeili,H.(2018). An investigation into the Effect of Alpha Ointment (Fundermol) on Perineal Pain relief following Episiotomy in Nulliparous Women. Journal of Midwifery and Reproductive Health, 6(1): 1149-1156.

Alomolhoda ,S., Amir ,S., Baghban, A., Esmaili ,S. (2014). Effects of Aloe Vera Gel on Breast Fissures in Breastfeeding Women, Pajoohande 19 (1) :13-17,

Anjum, S., Gupta ,A., Sharma ,D., Gautam, D., Bhan, S., Sharma, A., Kapil, A., Gupta,. B.(2016). Development of Novel wound Care Systems Based on Nanosilver Nanohydrogels of Polymethacrylic Acid with Aloe Vera and Curcumin. Materials Science and Engineering, 1(64):157-166.

Apurva , Sanjay ,.P, Yamini P., Rajshree,.B.(2016). Comparative Study Of Routine Versus Restricted Use Of Episiotomy In Primigravias. J. Evolution Med. 5(48),3086-89.

Attarha , M., Akbari Torkestani, N., Amiri Farahani, L., Heidari T. (2014). Comparison effect of Saline Normal with Povidon Iodine Solution. Avicenna J Nurs Midwifery care, 22 (1):32-4.

Bele S. (2014). Postnatal quality of life: A neglected research area in India. Perspectives in medical research journal,2(2), 1-2.

Carroli G, Mignini L (2009). Episiotomy for vaginal birth. Cochrane Database Syst Rev. 3,CD000081.

Davidson, N. (1974). Evaluating Postpartum Healing. J nurse midwifery, 19(2):6-8.

Dat ,AD., Poon, F., Pham ,KBT., Doust, J. (2012). Aloe Vera for treating acute and chronic wounds. Cochrane Database Syst Rev.;2:CD008762.

De-France, CJ., Podgorny, MN. (2003). National hospital discharge survey advance data. National Center for Health Statistics, 342.

Delaram, M., Dadkhah, N. (2014). Comparing the effects of Lidocaine Cream and Mefenamic Acid on Pain after Episiotomy. Women's Health Bulletin, 2(2):6-11.

Eduardo, S., Paulo, Q., Daniela, C., Madalena, C., João, A. (2016). The effectiveness of cleansing solutions for wound treatment: a systematic review. Journal of Nursing Referência, 4 (9), 134-40

Eghdampour, F., Jahdie, F., Kheyrkhah, M. , Taghizadeh ,M. , Naghizadeh ,S. , Hagani, H. (2013). The Impact of Aloe Vera and Calendula on Perineal Healing after Episiotomy in Primiparous Women: A Randomized Clinical Trial. Journal of caring sciences, 2(4), 279-286.

Eghdampour ,F., Jahdie ,F., Kheyrkhah ,M., Taghizadeh, M., Naghizadeh, S., Haghani, H. (2013) The Effect of Aloe Vera Ointment in Wound Healing of Episiotomy among Primiparous Women. The Iranian Journal of Obstetrics, Gynecology and Infertility, 15:25-31.

Eshghi ,F., Hosseinimehr ,SJ., Rahmani, N., Khademloo, M., Norozi ,MS., Hojati, O. (2010) Effects of Aloe Vera Cream on Post Hemorrhoidectomy Pain and Wound Healing: results of a randomized, blind, placebocontrol study. J Altern Complement Med,16:647-50.

Fernandez, R1., Griffiths ,R. (2012). Water for Wound Cleansing. Cochrane Database Syst Rev., $15 ;(2): C D 003861$.

Fodstad, K., Staff, AC., Laine K.(2014).Effect of different episiotomy techniques on perineal pain and sexual activity 3 months after delivery. Int Urogynecol J, 25:1629-37.

Golezar ,S., Ananas ,C. ( 2016). Effect on perineal pain and wound healing after episiotomy: a randomized double-blind placebo-controlled clinical trial. Iranian Red Crescent Medical Journal , 18(3): 21019.

Gomaa, R., Farrag, R., Abd El Raof, S., Mohamed, R. (2019).Effectiveness of Betadine versus Normal Saline Dressing on Episiotomy Wound Healing, Egyptian J of health care. 10(3): 193-206

Graham, I., Carroli, G., Davies, C., Medves, JM.( 2017). Episiotomy Rate Vary Worldwide: An update.Birth. 2005;32:219-23.

Hayes, S M. (1999).Lichen Planus: Report of Successful Treatment with Aloe Vera. General Dentistry: 47,(3): 268-272.

Heggers, J P., Kucukcelibi, A., Stabenou, C., Ko, F., Broemeling, L D., Robson ,M C. (1995) Wound Healing Effects of Aloe Gel and Other Topical Antibacterial Agents in Rat Skin. Phytotherapy Research, 9(6):455-457.

Hill P.(1990). Psychometric Properties Of The REEDA. J nurse midwifery; 35(3):162-165

Howard, D., DeLancey, J O., Burney, R E. (1999) Fistula-in-and after Episiotomy. Obst. and Gynae. 93:800-802.

Jiang, H., Qian, X., Carroli, G., Garner, P. (2017) .Selective Versus Routine Use Of Episiotomy For Vaginal Birth (Review). Cochrane Database, 2,CD000081.

Koli, P. (2018). The Effectiveness Of Aloe Vera Gel Application On Episiotomy Wound Healing Among Mothers In Early Puerperal Period. Thesis for M.sc (N) Obstetrics \& Gynecology. Jaipur, Rajasthan.

Kumar ,N., Shameem U., Kollu ,P., Kalyani ,RL., Pammi, SVN. (2015). Green Synthesis of Copper Oxide 
Nanoparticles Using Aloe Vera Leaf Extract and Its Antibacterial Activity against Fish Bacterial Pathogens. BioNanoScience, 5(3): 135-139.

Maenthaisong. R., Chaiyakunapruk, N., Niruntraporn, S., Kongkaew, C. (2007) The Efficacy of Aloe Vera Used for Burn Wound Healing: A systematic Review. Burns, 33:713-8

Mahmoodi, F., Mobaraki ,A. (2015) .Assessment of Effects of Kegel Exercises on Reduction of Perineal Pain after Episiotomy in Primiparous Women. The Iranian Journal of Obstetrics, Gynecology and Infertility; 17(95):18-25.

Makvandi , S., Abbaspour, M. , Aminfar, S . (2014). The Effect of Local Gentamicin Solution on Episiotomy Healing: A Randomized Controlled Clinical Trial. Iranian Journal of Obstetrics Gynecology and Infertility, $16(88): 21-38$

Malek H,A., Ghaffarzadegan, R., Alizadeh, Sh .A., Ghaffarzadegan, R., Haji Agaei, R., Ahmadlou ,M. (2013) .Effect Of Aloe Vera Gel Compared To 1\% Silver Sulfadiazine Cream On Second-Degree Burn Wound Healing. Complement Med J facul Nurs Midwif,3(1):418-28.

Melzac, R., Ketaz, J.. Pain Measurement in Persons In Pain : Churchill Livingstone: London .1994; 337-51.

Molazem, Z., Mohseni ,F., Younesi ,M., Keshavarzi ,S. (2014). Aloe Vera Gel and Cesarean Wound Healing; A randomized Controlled Clinical Trial. Glob J Health Sci., 7:203-9.

Nazari, S., Arasteh, F E., Shobeiri ,F.,shayan, A., Parisa ,P.(2019) Effect Of Aloe Vera Gel On Perineal Pain And Wound Healing After Episiotomy Among Primiparous Women: A randomized clinical trial. The Iranian Journal of Obstetrics, Gynecology and Infertility, 21(11), 44-51.

Pasc, A., Navolan, D., Pușcașiu, L., et al (2019) .A Multicenter Cross-Sectional Study of Episiotomy Practice in Romania. J Eval Clin Pract ,25:306-311.

Pooja Ms.(2018)The Effectiveness Of Aloevera Gel Application On Episiotomy Wound Healing Among Mothers In Early Puerperal Period Of Selected Maternity Hospitals, Jaipur, Rajasthan. International Journal of Science \& Engineering Development Research,3(5),289 - 294.

Priddis, H., Schmied, V. Dahlen, H. (2014) .Women's experiences following severe perineal trauma: A qualitative study. BMC Women's Health. BioMed Central, 14(1), 32.

Qian, Y., Yaoa, J., Russelc, M., Chena ,K., Wangd, X. (2015). Characterization of Green Synthesized NanoFormulation ( $\mathrm{ZnO}-$ A.vera) and Their Antibacterial Activity against Pathogens. Environmental Toxicology and Pharmacology, 39 (2); 736-746.

Reynolds,T., Dweck, AC. (1999) .Aloe Vera Leaf Gel: A Review Update.Journal of Ethnopharmacology, 68, (13); 3-37.

Rezazadeh, F., Moshaverinia, M., Motamedifar, M., Alyaseri, M. (2016). Assessment of Anti HSV-1 Activity of Aloe Vera Gel Extract: an In Vitro Study. J Dent (Shiraz), 17(1): 49-54.

Sabzaligol, M., Safari, N., Baghcheghi, N., Latifi „M., Koohestani, HR., Bekhradi, R., Taghizadeh M., Zareie, F.(2014) The Effect of Aloe Vera Gel on Prineal Pain \& Wound Healing after Episiotomy, Complementary Medicine Journal Arak University of Medical Sciences 4(2): 766-775

Sahu, PK., Dayal Giri, D., Singh R, et al. (2013). Therapeutic and medicinal uses of Aloe Vera: a review. Pharmacol Pharm,4:599-610.

Shahrahmani, H., Kariman ,N., Jannesari, S., Ghalandari ,S., Asadi, N. (2016). A Systematic Review On The Type Of Treatment Methods To Reduce Pain And Improve Wound Healing In Iran. The Iranian Journal of Obstetrics, Gynecology and Infertility,19(9):17-31.

Somboonwong, J., Thanamittramanee, S., Jariyapongskul, A., Patumraj, S.(2000) .Therapeutic Effects of Aloe Vera on Cutaneous Microcirculation and Wound Healing in Second Degree Burn Model in Rats. $J$ Med Assoc Thai.83:417-25.

Stanley, MC., Ifeanyi ,OE., Eziokwu, OG. (2014). Antimicrobial Effects of Aloe Vera on Some Human Pathogens. Int.J.Curr. Microbiol.App.Sci.3 (3): 1022-1028.

Steen, M., Cummins, B.(2016). How to alleviate perineal pain following an episiotomy. Nurs Stand.,30;30(31):34-7.

Van Limbeek, S., Davis ,D., Currie M. ,Wong, N.(2016). Non-Surgical Intrapartum Practices For the Prevention Of Severe Perineal Trauma: A Systematic Review Protocol. JBI Database System Rev Implement Rep,14(4):30-40.

Tafazolie, M., Saedie, R., Rebatsanghie, MG., Mazlom, SR. (2010). Aloe Vera Gel Versus Lanolin Ointment In The Treatment Of Nipple Sore: A Randomized Clinical Trial. Tehran University Medical Journal,67(10): 699-704.

Varaei, S., Atadabili, FM., Itani, PS., Ranjbar, H.(2017) The Effect of Aloe Vera Gel and Nitrofurazone on Dressing Related Pain of Superficial Burn Wounds. World J Plast Surg. ;6(2): 254-256. 
World health organization (2018). WHO recommendations: intrapartum care for a positive childbirth experience. Geneva: World Health Organization;. Licence: CC BY-NC-SA 3.0 IGO.

(https://apps.who.int/iris/bitstream/handle/10665/2978924155021/9789241550215eng.pdf\%3bjsessioni

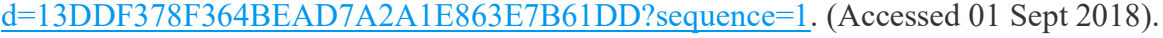

Yagi, A., kabash A., Mizuno, K., Moutafa ,SM., Khalifa ,TI., Tusuji ,H. (2003). Radical Scavenging Glycoprotein Cyclooxygenase-2 and Tthromboxane A2 Synthase from Aloe Vera Gel. Planta Med J, 69:269-71.

Zetterstrom, J., Lopez, A., Anzen, B., Norman, M., Holmstron, B., Mellgren, A.(1999) Anal sphincter tears at vaginal delivery: risk Factors and Clinical Outcome of Primary Repair. Obst. and Gynae. 94:21-28. 